\title{
How to Measure Scope Variables when no Metrics Exist: Application to Landscape Quality Measurement and Hedonic Price Evaluation
}

\begin{abstract}
Nils Soguel*1
Alexandre Tangerini*

and Jacques Pictet ${ }^{* *}$

Landscape is an example of a non-market good where no metrics exist to measure its quality. The paper proposes an original methodology to nevertheless estimate scope variables in those circumstances, allowing then to better test if people's willingness-topay for such good is sensitive to the scope. The methodology is based on techniques developed in the context of multicriteria decision analysis. It is applied to assess the quality of the landscape of several Swiss alpine resorts. This assessment is then used as an explanatory variable in a hedonic price function to explain the rent of apartments and to derive an implicit price of the landscape quality.
\end{abstract}

scope effect - landscape quality - landscape value - macbeth - silent negotiation cardinal data - hedonic price method

\section{Comment mesurer les variables d'envergure lorsqu'aucune métrique n'existe: application à la mesure de la qualité de paysage et à l'évaluation des prix hédonistes}

La paysage est l'exemple d'un bien non marchand pour lequel il n'existe pas de métrique permettant d'en mesurer la qualité. Cette contribution propose une méthodologie novatrice pour, malgré tout, estimer des variables d'envergure dans de telles circonstances, afin de mieux tester si la disposition à payer des individus est sensible à l'envergure. La méthodologie se fonde sur des techniques développées en analyse multicritère de la décision. Elle est appliquée pour évaluer la qualité du paysage de plusieurs stations alpines suisses. Les résultats sont ensuite utilisés comme variable explicative du loyer des appartements dans une fonction de prix hédonistes afin de déterminer le prix implicite de la qualité du paysage.

1. Corresponding author: nsoguel@idheap.unil.ch. The research benefited from the support of the Swiss National Research Foundation allocated as part of the National Research Program 48 " "Landscapes and habitats of the Alps".

* Institut de hautes études en administration publique-IDHEAP/Swiss Graduate School of Public Administration, University of Lausanne, Switzerland

** Bureau d'aide à la décision Pictet \& Bollinger, Lausanne 
effet d'envergure - qualité du paysage - valeur du paysage - macbeth - négociation silencieuse - données cardinales - méthode des prix hédonistes

Codes JEL C44; C81; 026; 051

In many instances, literature on the evaluation of non-market goods considers hedonic price (HPM) and contingent valuation methods (CVM) as alternative or even competing techniques. However, both share identical methodological challenges when modelling the willingness-to-pay function, or first the hedonic price function, in the case of HPM.

Estimating this function is indeed more critical in the case of HPM as that of CVM. With HPM, this becomes absolutely necessary when typically identifying how much of a property value differential is due to a particular disparity in the considered non-market good (e.g. the landscape quality as an explanatory variable).

Valuing the non-market good in the CVM directly from the willingness-topay (WTP) stated by the respondent is possible by using the mean or the median. However, modelling the WTP allows the researcher to test for the validity of the survey responses. One common acid test of the continuity and strict monotonicity of a respondent's preferences, often referred to as a scope test, looks at whether a respondent is willing to pay more for a good larger in scope, either in a quality or quantity sense (Carson et al. [2001]).

For certain goods, scope variables are easy to obtain using existing metrics and measurement procedures. Some of these procedures are based on chemical, physical, electronic, or statistical techniques: air quality in micrograms of pollutants per cubic meter, quietness in decibels, injuries and fatalities with incidence and prevalence measures (for examples, see Hidano [2002]). Further, the perceived level of a given non-market good might impact more on the WTP than the technically measured one.

For several goods, especially when concerning perceived effects, the scope is much more difficult to measure. The landscape or scenic resources are instances of goods where no pertinent qualitative or quantitative metrics exist. As a result, scenarios and variables utilize unsophisticated measurement procedures. Using dummies to express the good or poor aesthetic quality is an example. Ranking or Likert-style rating is also used.

The methodological aim of the paper is to propose a more sophisticated methodology based on two complementary techniques developed in the context of multiple criteria decision analysis. Firstly, the MACBETH technique (Measuring Attractiveness by a Categorical Based Evaluation Technique) is used to define numerical values based on verbal statements (Bana e. Costa [2001]). This is then complemented by the silent negotiation technique, a heuristic technique used for the purpose of reaching a consensus within a group of people (Pictet \& Bollinger [2005]). From a methodological point of view, the paper also aims at using the estimated variable as explanatory in the hedonic price function.

The empirical objective is to apply the methodology to assess the quality of the landscape of several Swiss alpine resorts, and then use this assess-

REP 117 (5) septembre-octobre 2007 
ment as the explanatory variable in a hedonic price function in order to explain the rent of apartments in these resorts and to derive an implicit price of the landscape quality.

The paper is organized into six sections. Section 1 addresses the issue of the scope effect in relationship with the measurement of the non-market variable as a prerequisite to valuation techniques. Section 2 then proposes a methodology to measure non-market variables when no metrics exist. Section 3 utilises the proposal to measure the aesthetic landscape quality of six Swiss alpine ski resorts. Subsequently, section 4 uses this estimated landscape quality measure as an explanatory of the rent paid by tourists in the hedonic price function. Finally, the last section offers concluding remarks.

\section{Scope effect, measurement of the non-market variables, and valuation techniques}

Economists usually assume that individuals base their choices on observable and well-understood measures of goods and services. This may be true for relatively homogeneous commodities, yet rather unlikely for complex and heterogeneous ones. In these latter cases, measurements use metrics or proxies that individuals may not be able to easily interpret. For years, economic psychologists have identified this deficiency when analysing consumer decision-making behaviour (Singh [1988]). Payne [1982] suggested that buying decisions depend upon perceptual elements. Thus, using a person's subjective assessments of attributes as part of the framework when modelling demand for non-market goods is essential (Poor et al. [2001]).

As for the CVM, much has been written in literature to investigate the scope effect that arises when different objectively-measured amounts of a given non-market good occasionally have the same willingness-to-pay (Desvousges et al. [1993]). However, the measurement of the scope variable remains until now quite rudimentary, especially when regarding an individual's subjective perception. Schwab Christe and Soguel [1996] provide an example when estimating the WTP of the reduction of risk in being the victim of a road accident. The perceived difference in severity between the considered injury categories (e.g. slight injury, partial or permanent disability) was estimated by asking respondents to place each category on a graduated scale of severity. For each type of injury, the obtained degree of severity was then used as an explanatory variable of the WTP to reduce the risk of being a victim. In this particular instance, the variable seemed to influence significantly the WTP and correlate with the expected positive sign. However, the process appears rather unsophisticated, especially when its aim is to test a possible scope bias. The same type of process is used in cases where no objective or metrics exist.

The measurement of the scope variable is even more crucial in the estimation of the hedonic price equation. The basic idea of the technique is to 
regressing house price on a package of inherent attributes (Rosen [1974], Freeman [1979], Boyle \& Kiel [2001]). The computed hedonic equation helps explain house prices in terms of housing characteristics (number of rooms of the flat, age, floor) and neighbourhood attributes. Each of these peculiarities is assumedly reflected implicitly in the price. An increasing number of models integrate measures of non-market quality. However, most of the existing studies mainly model non-market quality or amenity where common and objective measures exist. These measures are obtained using established metrics, specialized equipment, and standardized procedures to take measurement. For instance, Graves et al. [1988] utilized visibility data measured as total suspended particulates in the case of air quality, Nelson [1978] employed decibels with respect to noise pollution, and Feenberg \& Mills [1980] implemented measures of turbidity in the case of water quality.

Few hedonic studies actually aim at estimating the impact of landscape on property values, though the seminal study about landscape valuation by Brush \& Shafer [1975] suggested that a consumer's evaluation of real estate overlooking a given natural scene correlates highly with the scene's predicted preference scores. Nasar [1983] also stressed that sight can be considered the most important sense in the immediate interaction with our surroundings.

Measuring the variable "landscape" is indeed a particularly complicated issue. Different approaches to landscape assessment have been developed by natural scientists (Zube et al. [1982]; Daniel \& Vining [1983]), with the human perception-based approach being the most dominant. Human observers express their preferences (choices, likes, and dislikes) and either judge or rate visual aesthetic qualities (including scenic quality, visual quality, and scenic beauty of a "real" environment or surrogates, principally from photographs of the landscapes in question). This approach derives from the psychophysical tradition in psychology where human perceptual responses are used to gauge properties of objects, resulting in the creation of indices to refer to objects (Daniel \& Meitner [2001]). However, the connection between these types of approaches and hedonic studies remains to be implemented.

A distinction should be made between the hedonic studies investigating the impact of benefiting from a view (existence of a view) on housing price and those related to the aesthetic quality of the landscape, which can be feasibly viewed.

Bourassa et al. [2003] list only 35 hedonic studies analyzing the implicit price of benefiting from a view over various sites (river, lake, ocean, mountains, forest, etc.). In most of these studies, the existence of a view impacts the house price in a positive way. Usually, this is minimally accounted for by means of a dummy variable (with or without a view). Traditional ways to collect data are in situ by visual observations, manually from maps or photographs. These methods are highly time-consuming and potentially biased. Certain recent studies have taken advantage of geographic information systems to analyze topographic and remotely sensed land cover data (Powe et al. [1997]; Salvi et al. [2004]).

Attempts to model the impact of landscape quality on house prices are even less numerous (Li \& Brown [1980]; Des Rosiers et al. [2002]). Bourassa

REP 117 (5) septembre-octobre 2007 
et al. [2003] introduced indicators to reflect the panoramic view over expanses of water for conurbations of the city of Auckland, New Zealand, as well as a series of variables measuring the average landscape and building quality in the neighbourhood. Benson et al. [1998] led the only study that examined the impact of different types and scope of the view on property values. All these studies confirm the difficulty of constructing explanatory variables that reflect appropriately the aesthetic quality of the landscape - i.e. that limit error-in-variables problems and measurement errors (Atkinson \& Crocker [1987]).

\section{A methodological proposal to measure variable when no metrics exist}

\subsection{Transforming ordinal ranks into cardinal figures}

The use of scales helps to comprehend complex concepts, like the quality of a landscape. Fundamentally, two main types of scale exist: the cardinal and the ordinal scale. The cardinal scale has regular divisions based on levels or stages (including an occasionally conventional point of origin) that can be subdivided, enabling measurements and calculations. For example, space and time have scales that enable calculations, such as speed (distance/time). Basic operators, such as addition, subtraction, multiplication, and division, consequently are significant and refer to a ratio scale (e.g. $4 \mathrm{~m} / \mathrm{s}$ is twice $2 \mathrm{~m} / \mathrm{s}$ ).

The ordinal scale functions differently. The only information available is the relative position of objects. For example, A is "as beautiful as" or "more beautiful than" B. Accordingly, the numbers that could be associated with each object represent the ordered rankings (first, second, third, etc.) and therefore cannot be manipulated using basic operators. As emphasised by Santos ([1998] p.25), "the fact that landscape quality judgments have no cardinal dimensions means they do not support algebraic operations, such as sums or products".

As a result, in order to be able to take non-cardinal dimensions into account in numerical evaluations, adding information to the ordinal ranking is logical. This information concerns the difference that exists between two pairs of objects. For example, one can ask an individual to express their opinions on statements such as "Is the difference between A and B greater than one between $C$ and D?". Difficulty therefore lies in the appropriate processing of the responses provided. 


\subsection{Measuring attractiveness by a categorical based evaluation technique}

Several multicriteria decision techniques exist and allow comparative judgments (e.g. analytical hierarchical process). However, MACBETH (Measuring Attractiveness by a Categorical Based Evaluation Technique) is the only one that allows validating judgments by theoretical and semantic consistency checking (Salomon \& Montevechi [2001], p.415). The tool has also been developed since the early 1990's (Bana e Costa [2001]; Bana e Costa et al. [2003]). MACBETH involves five stages:

1. Ordering of the objects by decreasing level of attractiveness, with equal rankings allowed. In the interest of simplicity, the sequence of ordered objects is named $(A, B, C, D, E)$. All of the pairs $(A, B ; A, C ; .$.$) form a square$ matrix. As can be seen in Table 1, only the upper triangle of the square matrix is of interest ${ }^{2}$.

2. For each pair of objects (e.g. A, B), the difference in attractiveness between $A$ and $B$ is defined by means of a verbal statement (e.g. "no difference", "very weak", "weak", "moderate", "strong", "very strong", and "extreme"). This information is only meaningful in the context of the differences provided for the other pairs (e.g. C, D). MACBETH can also function with the minimum of $(n-1)$ responses (generally the diagonal line of successive pairs), based on the hypothesis that the difference of the other pairs is positive (Table 1). The differences within remaining pairs (e.g. B, D) are finally imposed as being positive by default.

3. MACBETH verifies the consistency of the responses provided. The test is easy to comprehend. If the differences between $A$ and $B$ and between $B$ and $C$ are "moderate", the difference between $A$ and $C$ is at least "moderate". More complex tests also take place, yet these are beyond the scope of this paper.

4. MACBETH then calculates numerical values or scores that are compatible with the verbal statements provided. The resulting scale may therefore be considered as cardinal. Note however that these compatible numerical values are not more precise than the verbal statements on which they are based.

2. This derives from the ordering of the objects. If $A$ is more attractive than $B$, there is no "no difference" or "positive difference" in favor of $B$. The main diagonale $(A, A ; \ldots)$ is by definition filled with "no difference".

REP 117 (5) septembre-octobre 2007 
Table 1. Matrix form representing the rankings of five objects with differences in attractiveness and corresponding scores computed with MACBETH

\begin{tabular}{|c|c|c|c|c|c|c|}
\hline & A & B & C & D & E & Score \\
\hline A & no & very strong & positive & positive & positive & 100.00 \\
B & & no & very weak & positive & positive & 54.55 \\
C & & & no & moderate & positive & 45.45 \\
D & & & & no & weak & 18.18 \\
E & & & & & no & 0.00 \\
\hline
\end{tabular}

\subsection{Silent negotiation}

Like many decisional aids, MACBETH was designed for use by a single decision-maker. When used for the purpose of reaching agreement between several actors or stakeholders, the way of interaction should be adapted. This can be accomplished in various ways. The silent negotiation approach voluntarily limits the discussion of motivations in favour of the statement of preferences, so points of convergence and divergence can easily be identified (Pictet \& Bollinger [2005]). This process is carried out during moment of silence. The rules of the game are explained before each silent period. Afterwards, the results are discussed in order to alleviate the accumulated tensions, generally because individuals are not used to interact in silence.

The silent negotiation approach corresponds efficiently with MACBETH if one takes care of two aspects. First, in order to categorise the objects according to the phase 1 of MACBETH, the successive participants can make a given number of changes in the ranking of the objects (i.e. shifting of an object one ranking up or down). Several rounds of changes may be necessary until a single ranking emerges.

Second, the differences between the objects are then defined a priori (e.g. as a "moderate" difference). According to phase 2 of MACBETH, the participants can subsequently make a given number of changes, shifting upwards or downwards of a difference level. In turn, several rounds of changes may be required until a stable situation emerges, i.e. until participants no longer want to amend the differences between any single pair of objects.

There is no theoretical limit to the number of individuals participating in the silent negotiation. There is no theoretical limit either to the number of considered objects. The only limitation is a practical one: the larger the number of participants and/or objects, the longer it takes to reach a stable situation. 


\section{Measuring the landscape quality of Swiss alpine resorts}

\subsection{Description of the experiment}

The proposed framework was used to assess the quality of the landscape in six selected ski resorts, all located in the Swiss canton of Valais, namely Anzere, Champery, Grimentz, Haute-Nendaz, Ovronnaz, and Verbier. A group of "experts" was brought together for an evaluation session. The group comprised of people from different sectors to incorporate a number of various perceptions into the landscape evaluation. The group included representatives from tourism (specifically employees of tourism offices, obviously not in the selected resorts), ecology and tourism research sectors, and public bodies. The evaluation session began with an introductory phase that explained the objective of the study and the reasons for the participants' involvement.

Members of the group were then presented with the objects for comparison. They were shown a series of photographs of the landscape to be valued. The landscape was depicted using one panoramic photograph of the most prominent view from the ski resort ${ }^{3}$. The photographs were taken at the end of winter 2002-03. Therefore, they all show a snow-covered landscape, attempting to maintain consistency in terms of exposure and brightness. The six photographs were identified using letters, as the use of resort names could have prompted biased judgments. An opportunity for discussion was also provided to clarify any possible doubts and questions of the participants. The participants were then requested to silently complete the two evaluation phases:

1. To rank the photographs from the most to the least beautiful, with equal rankings allowed. The use of photographs corresponds well with the silent negotiation approach. The photographs were placed on a single line (equal ranking) and each participant was allowed to move the photographs up or down. Each successive participant was authorized three changes (for example, shifting a photograph 3 times up, or shifting a photograph up once and two photographs down once) and the game lasted an unlimited number of rounds among the participants until a stable ranking was reached.

2. Once the ranking was established, the participants were asked to verbally, but silently, define the difference between the pairs of objects using a verbal (ordinal) scale comprising of seven statements written on small cards, ranging from "no difference" to "an extreme difference". At the beginning, the difference between each successive pair of object was initiated

3. These prominent views were not selected randomly. We took the photographs after consultations with estate agents and/or members of the tourism offices in each location.

REP 117 (5) septembre-octobre 2007 
with a "moderate difference" written card. As before, only three changes per participant and round were possible (for example, the first participant could change the "moderate" card for an "extreme" card between a single pair, or change the moderate cards for "weak difference" cards between three pairs of objects).

With nine participants and six landscapes to assess, the negotiation lasted less than one hour, including the presentation of the aim of the study and the explanation on how to proceed through the negotiation.

\subsection{Results}

Table 2 shows the results of the ranking and the verbal statement of the differences between each pair of objects in matrix form. The landscape of Champery $(\mathrm{C})$ holds the top position in the ranking. It was therefore conceived as being of better aesthetic quality than the landscape of Verbier (V). Moreover, the qualitative difference between these two landscapes, according to the preferences of the experts, is defined as "strong". Similarly, the difference between the landscape of Ovronnaz (O) and Grimentz (G) is "weak". All these differences explain the disparity between scores. The scores are standardized for a scale ranging from zero (the landscape deemed least attractive by the participants, in our case Haute-Nendaz) to 100 (the most attractive landscape, Champery). Figure 1 illustrates both the ranking and the score of each resort. Given that the verbal statements are rather crude, MACBETH generates an interval where the computed score can oscillate, yet remains consistent with the verbally defined difference between objects. The intervals are also represented in graphic form, making possible to visually grasp the scope of the differences that qualify each pair of landscapes. Sometimes, the intervals overlap, as it is the case here for Ovronnaz and Grimentz. This does not mean that the former could be below the latter. If a higher score was chosen for Grimentz - i.e. 52.00 - the intervals would be modified and the score of Ovronnaz should remain higher than that.

\section{Table 2 Results of the evaluation of the landscape quality} of six Swiss ski resorts

\begin{tabular}{|c|c|c|c|c|c|c|c|}
\hline & C & V & 0 & G & A & $\mathrm{H}-\mathrm{N}$ & Score \\
\hline C & no & strong & positive & positive & positive & positive & 100.00 \\
\hline V & & no & moderate & positive & positive & positive & 75.00 \\
\hline 0 & & & no & weak & positive & positive & 56.25 \\
\hline G & & & & no & strong & positive & 43.75 \\
\hline A & & & & & no & moderate & 18.75 \\
\hline $\mathrm{H}-\mathrm{N}$ & & & & & & no & 0.00 \\
\hline
\end{tabular}




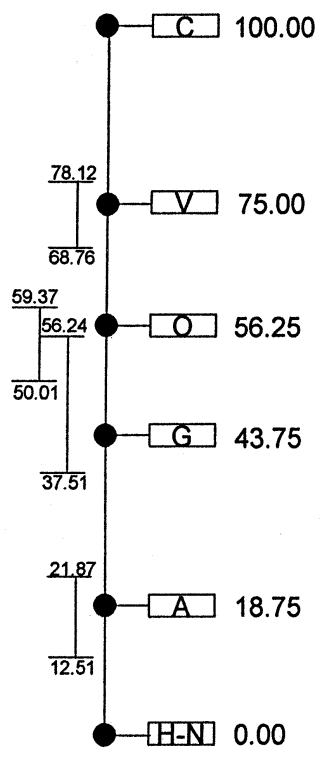

C: Champery

V: Verbier

O: Ovronnaz

G: Grimentz

A: Anzere

H-N: Haute-Nendaz

Figure 1. Graphical representation of the MACBETH scores for aesthetic quality of the landscape for six Swiss ski resorts and intervals respecting the consistency of the verbal statements

\section{Modelling the hedonic price function using the estimated landscape quality}

The hedonic price analysis is based on a sample of 402 apartments rented out to tourists in the studied resorts during the 2002-03 winter season. Apart from the landscape quality variable, the data collected for this study derived from various sources. Real estate agents in each resort were first called upon in order to benefit from data relating to the intrinsic characteristics of the buildings and apartments. We were thus able to collect 57 intrinsic variables for each apartment in the sample (17 concerning the building and 40 for the apartment itself). The local tourist offices and authorities permitted us to establish 20 variables relating to the local characteristics of the resorts. The characteristics of the neighbourhoods, or the distance separating the buildings from several "strategic" locations in the resort (ski lifts, resort 
centres, and grocery stores), were surveyed with either GIS tools or fieldwork. The hedonic price function is specified empirically as follows:

$$
H_{i}=H\left(I_{i}, L_{i} Q_{i}\right)
$$

$H_{i}$ is the gross weekly rent, including bills, paid by tourists for apartment $i$. $I_{i}, L_{i}$, and $Q_{i}$ designate the vectors of the intrinsic, local neighbourhoods' characteristics and the quality of the landscape.

The hedonic price function is first estimated using the general transformation proposed by Box and Cox [1964] in order to determine the functional form that maximizes the likelihood (MLE) of the hedonic function ${ }^{4}$. The Box-Cox coefficient equals 0.06 and has a $95 \%$ probability to be in the range $-0.03<\lambda<0.15$. This range, together with the fact that the estimated coefficient is very close to zero, permits to logarithmise the dependent variable and to compute an OLS estimation, allowing a more intuitive interpretation of the coefficients. The results of the estimation are presented in Table 3. Each explanatory variable is retained on the basis of the three following criteria: (a) the variable presents the theoretically expected sign or the sign located in several previous studies; (b) the variable is clearly significant ; $(c)$ the variable does not present a critical risk of multicollinearity with other retained variables.

Assessed according to usual statistical criteria, the results appear consistent. There is no sign of multicollinearity, according to the variance inflation factors and the condition number, and no sign of heteroscedasticity when applying the Breuch-Pagan and Cook-Weinberg tests. The eight independent variables retained in the hedonic function justify more than $70 \%\left(R^{2}\right.$ corrected) of the rent variability (i.e. its value in logarithmic form). The quality of the landscape influences without any doubt the variation in rents. Furthermore, according to the computed beta-coefficients, this variable influences rent the most behind the number of rooms and the average length of ski runs. If MACBETH cardinal scale of landscape beauty were postulated to be continuous, one could consider that an increase in the aesthetic quality of 10 percentage-points triggers a rent increase of over $2 \%$. In reality, we can only compare the six resorts in the sample with each another, since the obtained values are relative. Table 4 presents the simulated rent according to the landscape quality assessed using MACBETH and holding other characteristics of the apartment $\left(I_{i}, L_{i}\right)$ constant at their average value. Considering the two extreme scores of the landscape quality variable, the rent for an apartment in Champery is $26 \%$ higher than the same apartment in Haute-Nendaz.

4. The general transformation, here of the dependent variable $H_{i}(>0)$ is the following: $H_{i}^{(\lambda)}=\frac{\left(H_{i}^{\lambda}-1\right)}{\lambda}$

where $\lambda$ is a Box-Cox parameter determined to normalize the error distribution. The transformation allows a great deal of flexibility in the search for an appropriate functional form. The transformation can possibly be linear $\lambda=1$ or a natural logarithm $\lambda=0$.

REP 117 (5) septembre-octobre 2007 
Table 3. Descriptive statistics and OLS estimation of the hedonic price function (semi-log)

\begin{tabular}{|c|c|c|c|}
\hline $\begin{array}{l}\text { Independent variables (in order of importance of } \\
\text { the absolute value of the beta-coefficients) }\end{array}$ & $\begin{array}{l}\text { Descriptive } \\
\text { statistics }^{b}\end{array}$ & $\begin{array}{l}\text { Estimation } \\
\text { results }^{c}\end{array}$ & $\begin{array}{l}\text { Beta } \\
\text { coefficients }\end{array}$ \\
\hline Constant & & $\begin{array}{c}5.599 * * \\
(87.86)\end{array}$ & \\
\hline $\begin{array}{l}\text { Number of rooms in the apartment (excluding } \\
\text { kitchen and bathrooms) }\end{array}$ & $\begin{array}{c}2.7 \\
(1.1)\end{array}$ & $\begin{array}{l}0.239 * * \\
(21.32)\end{array}$ & 0.63 \\
\hline $\begin{array}{l}\text { Average length of the ski runs (ratio between the } \\
\text { length of the runs in kilometres and the number } \\
\text { of ski lifts) }{ }^{d}\end{array}$ & $\begin{array}{c}3.6 \\
(1.0)\end{array}$ & $\begin{array}{c}0.114^{* *} \\
(7.37)\end{array}$ & 0.27 \\
\hline $\begin{array}{l}\text { Landscape quality (MACBETH score on a scale of } \\
0 \% \text { to } 100 \% \text { ) }\end{array}$ & $\begin{array}{c}0.4 \\
(1.1)\end{array}$ & $\begin{array}{l}0.232 * * \\
(5.35)\end{array}$ & 0.18 \\
\hline $\begin{array}{l}\text { Fireplace (dummy with value } 1 \text { if the apartment } \\
\text { has a fireplace) }\end{array}$ & $\begin{array}{c}0.5 \\
(0.5)\end{array}$ & $\begin{array}{c}0.117^{* *} \\
(4.59)\end{array}$ & 0.13 \\
\hline $\begin{array}{l}\text { Infrastructures (index of the stock of infrastructure } \\
\text { available at the resorts: grocery stores, bars, num- } \\
\text { ber of tourist beds, night clubs, restaurants, } \\
\text { sports stores, real estate agents) }\end{array}$ & $\begin{array}{l}15.5 \\
(9.4)\end{array}$ & $\begin{array}{l}0.006^{* *} \\
(3.85)\end{array}$ & 0.12 \\
\hline $\begin{array}{l}\text { Distances (sum of the distances to the resort's } \\
\text { main infrastructures: ropeways, grocery stores, } \\
\text { and resort centres) }\end{array}$ & $\begin{array}{c}1.7 \\
(1.1)\end{array}$ & $\begin{array}{c}0.0299 * \\
(2.45)\end{array}$ & 0.07 \\
\hline $\begin{array}{l}\text { Age of the building (number of years since the } \\
\text { construction, in hundred of years) }\end{array}$ & $\begin{array}{c}0.261 \\
(0.152)\end{array}$ & $\begin{array}{l}-0.197^{*} \\
(-2.55)\end{array}$ & -0.07 \\
\hline $\begin{array}{l}\text { Benefit from a view (surface of landscape visible, } \\
\text { measured in square decametres, within a radius } \\
\text { of } 20 \text { meters from each facade of the building) }\end{array}$ & $\begin{array}{c}5.8 \\
(4.7)\end{array}$ & $\begin{array}{l}0.005^{*} \\
(2.01)\end{array}$ & 0.05 \\
\hline $\begin{array}{l}\mathrm{N} \\
R^{2} \text { corrected } \\
\mathrm{F}\end{array}$ & & $\begin{array}{c}402 \\
0.74 \\
143.97\end{array}$ & \\
\hline
\end{tabular}

a. The dependent variable is the natural logarithm of the gross weekly rent during the period of February to March 2003 (including heating costs and other bills). The average nominal weekly rent equals $1156 \mathrm{CHF}$, with a standard deviation of 576 . At the time of writing, $1 \mathrm{CHF}=0.622 €$.

b. Average and standard deviation in brackets.

c. $T$-values are shown between parentheses under the estimated parameters. Coefficients with double asterisk are significant to $99 \%$. Those with a single asterisk are significant to $95 \%$ (bilateral test).

d. This average length offers an estimate of the "rate-of-return" one can expect from each lift, in terms of the duration of the descent.

e. The infrastructure index is made up of several sub-indexes. Each of them measures the importance of a type of infrastructure relative to the total offered by the six resorts. For example, Verbier hosts $13(34 \%)$ of the 38 bars of the six resorts $(100 \%)$ and 18 $(46 \%)$ of the sports stores. After averaging the percentages over the seven different types of infrastructure, Verbier offers the largest total infrastructure $(37 \%)$, and Grimetz and Ovronnaz the smallest (7\% each).

REP 117 (5) septembre-octobre 2007 
Table 4 Simulated weekly rents for an apartment when the landscape quality varies, holding average characteristics constant

\begin{tabular}{|l|c|c|}
\hline & $\begin{array}{c}\text { Landscape quality } \\
\text { (MACBETH score) }\end{array}$ & $\begin{array}{c}\text { Simulated weekly rent } \\
\text { for an average apartment }\end{array}$ \\
\hline Champery & 100.00 & 1175 \\
Verbier & 75.00 & 1109 \\
Ovronnaz & 56.25 & 1062 \\
Grimentz & 43.75 & 1031 \\
Anzere & 18.75 & 973 \\
Haute-Nendaz & 0.00 & 931 \\
\hline
\end{tabular}

Most of the other retained variables positively influence the rent. For example, an additional room increases the rent by about $24 \%$ and a fireplace by approximately $10 \%$. Longer ski runs and better-developed infrastructure also raise the rent. Additionally, the distance from the resort's main infrastructures positively affects the rent, signalling a tourists' need for quietness. Inversely, the age of the building negatively affects the rent.

One supplementary and relevant result is that benefiting from a view from the apartment also positively impacts the rent. This variable is a geometrical construct measuring the surface that can be seen through apartment windows. It takes into account the vertical and horizontal angles of vision from each window within a distance of 20 meters from the building.

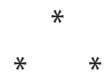

The empirical aim of this paper was to value, by means of the hedonic price technique, the implicit price of landscape quality, using as explanatory scope variable, a score established using two complementary techniques, namely MACBETH and the silent negotiation. Indeed, no metrics exist to calculate the aesthetic quality of the landscape. However, the hedonic price technique unquestionably requires a cardinal measurement to produce refined implicit prices, just as the contingent valuation technique needs one to adequately test if an individual's willingness-to-pay is sensitive to the scope of the good being valued.

The results show that the combination of these multicriteria techniques allows creating a scope variable that subsequently proves to explain significantly the variability of the rent. As expected, the higher the score (and the scope) reflecting the landscape quality, the higher the rent. As such, hedonic price modelling provides us with an external validation of the methodological proposal. This is a first piece of evidence that illustrates the proposal's ability to generate a cardinal variable, even though no metrics exist for this investigated non-market quality, and can successfully be used in valuation techniques.

Presently, the hedonic price method has mainly been used for evaluating non-market characteristics whose quality could be measured with instru- 
mental measurement scales. Here, the technique is used to measure the implicit price of an amenity where no measurement scale exists. Accordingly, our study reveals that combining multicriteria techniques and the hedonic price method broadens the field of application. In this sense, this solution promotes once more the hedonic price method versus competing techniques, such as contingent valuation.

\section{References}

ATKINSON S.E. and CROCKER T.D. [1987], "A Baysian Approach to Assessing the Robustness of Hedonic Property Value Studies", Journal of Applied Econometrics, 2, 27-45.

BANA E COSTA C.A. [2001], "The use of multi-criteria decision analysis to support the search for less conflicting policy options in a multi-actor context: case study", Journal of Multi-Criteria Decision Analysis, 10, 111-125.

BANA E COSTA C.A., DE CORTE J.-M. and VANSNICK J.-C. [2003], MacBeth, London School of Economics, Working Paper 03.56, London.

BENSON E.D., HANSEN J.L., SCHWARTZ A.L. JR. and SMERSH G.T. [1998], “Pricing Residential Amenities: The Value of a View", Journal of Real Estate Finance and Economics, 16[1], 55-73.

BOURASSA S.C., HOESLI M. and SUN J. [2003], What's in a view?, Geneva: Research Paper $N^{\circ} 79$, FAME-International Center for Financial Asset Management and Engineering, Geneva.

BOX G.E. and COX D.R. [1964], "An Analysis of Transformations", Journal of Royal Statistical Society, 2, 211-252.

BOYLE M.A. and KIEL K.A. [2001], "A Survey of House Price Hedonic Studies of the Impact of Environmental Externalities", Journal of Real Estate Literature, 9, 117144.

BRUSH R.O. and SHAFER E.L. [1975], "Application of a Landscape-Preference Model to Land Management", In Landscape Assessment: Values, Perceptions and Resources, Zube E.H., Brush R.O. and Fabos J.G. [eds.], p.168-181, Dowden, Hutchinson and Ross, Inc., Stroudsburg, Pennsylvania.

CARSON R.T., FLORES N.E. and MEADE N.F. [2001], "Contingent Valuation: Controversies and Evidence", Environmental and Resource Economics, 19[2], 173-210.

DANIEL T.C. and MEITNER M.M. [2001], "Representational Validity of Landscape Visualizations: The Effects of Graphical Realism on Perceived Scenic Beauty Of Forest Vistas", Journal of Environmental Psychology, 21[1] 61-72.

DANIEL T.C. and VINING J. [1983], "Methodological issues in the assessment of landscape quality", In Altman I. and Wohlwill J. [eds], Human Behavior and Environment, Vol.VI, Plenum, New York, 39-84.

DES ROSIERS F., THÉRAULT M., KESTENS Y. and VILLENEUVE P. [2002], “Landscaping and House Values: An Empirical Investigation", Journal of Real Estate Research, 23, 139-161.

DESVOUSGES W. H., JOHNSON F. R., DUNFORD R. W., BOYLE K. J., HUDSON S. P. and WILSON K. N. [1993], "Measuring Natural Resource Damages with Contingent Valuation: Tests of Validity and Reliability", in Hausman J. [ed.], Contingent Valuation: A Critical Assessment. North-Holland. Amsterdam.

REP 117 (5) septembre-octobre 2007 
FEENBERG D. and MILLS E.S. [1980], "Measuring the Benefits of Water Pollution Abatment", in Studies in Urban Economics, Mills E.S. [ed], Academic Press, New York, 177-181.

FREEMAN A.M. [1979], "Hedonic Prices, Property Values and Measuring Environmental Benefits: A Survey of the Issues", Scandinavian Journal of Economics, 81, 154-173.

GRAVES P., MURDOCH J.C., THAYER M.A. and WALDMAN D. [1988], "The Robustness of Hedonic Price Estimation: Urban Air Quality", Land Economics, 64, 200233.

HIDANO N. [2002], The Economic Valuation of the Environment and Public Policy: A Hedonic Approach, Cheltenham and Northampton: Edward Elgar.

LI M.M. and BROWN H.J. [1980], "Micro-Neighbourhood Externalities and Hedonic Housing Prices", Land Economics, 56, 125-141.

NASAR J.L. [1983], “Environmental factors, perceived distance and spatial behavior", Environment and Planning B: Planning and Design, 10, 275-281

NELSON J.P. [1978], Economic Analysis of Transportation Noise Abatment, Ballinger, Cambridge, Mass.

PAYNE J.W. [1982], "Contingent Decision Behavior", Psychological Bulletin, 92[2], 382-402.

PICTET J. and BOLLINGER D. [2005] "The silent negotiation or How to obtain collective information for group MCDA without excessive discussion", Journal of Multi-Criteria Decision Analysis 13[5-6], 199-211.

POOR P.J., BOYLE K.J., TAYLOR L.O. and BOUCHARD R. [2001], "Objective versus Subjective Measures of Water Clarity in Hedonic Property Value Models", Land Economics, 77[4], 482-493.

POWE N.A., GARROD G.D., BRUNSDON C.F. and WILLIS K.G. [1997], "Using a Geographical Information System to Estimate an Hedonic Price Model of the Benefits of Woodland Access", Forestry, 70, 139-149

ROSEN S. [1974], "Hedonic Prices and Implicit Markets: Product Differentiation in Pure Competition", Journal of Political Economics, 82, 34-35.

SALOMON V.A.P. and MONTEVECHI J.A. [2001], A compilation of comparisons on the analytic hierarchy process and others multiple criteria decision making methods: some cases developed in Brazil, $6^{\text {th }}$ International Symposium on the Analytic Hierarchy Process, Bern.

SALVI M., SCHELLENBAUER P. and SCHMIDT H. [2004], Preise, Mieten und Renditen: Der Immobilienmarkt transparent gemacht. Zürcher Kantonalbank, Zürich.

SANTOS J.M. [1998], The Economic Valuation of Landscape Change: Theory and Policies for Land Use and Conservation, Edward Elgar, Northampton MA.

SINGH H. [1988], "Investigating the Compatibility of Econometric Forecasts and Subjective Expectations: A Suggested Framework", Journal of Economic Psychology, 9, 233-249.

SCHWAB CHRISTE N.G. and SOGUEL N.C. [1996], "The Pain of Road-Accident Victims and the Bereavement of their Relatives: A Contingent-Valuation Experiment", Journal of Risk and Uncertainty, 13, 277-291.

ZUBE E.H., SELL J. L. and TAYLOR J.G. [1982], "Landscape perception: research application and theory", Landscape Planning, 9, 1-33. 
